\title{
Wind load effect on the lateral instability of precast beams on elastomeric bearing supports
}

\section{Influência da ação do vento na instabilidade lateral de vigas pré-moldadas sobre almofadas de apoio elastoméricas}
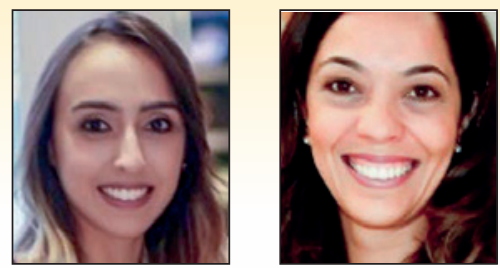

M. T. S A. CARDOSO a mariateresasacardoso@gmail.com https://orcid.org/0000-0001-9762-8918

M. C. V. LIMA

macris@ufu.br https://orcid.org/0000-0001-9641-474X

\section{Abstract}

The behavior of slender precast beams related to lateral stability in the transitional and in service phases is worrying. The presence of geometric imperfections aggravates and makes the problems of instability more susceptible. The main objective of this work is to evaluate the behavior of concrete beams on elastomeric bearings and to analyze the influence of variables such as: concrete strength, wind load and bearing compression stiffness. For the numerical nonlinear analysis the software ANSYS based on the Finite Element Method was used. The analyses show that the influence of the strength of the concrete is significant in the lateral stability of the beam. The wind load represents a considerable decrease in the contact (lift off) between the beam and the bearing. Finally, the combination of these factors can result in a critical stress situation in the beam, and it is not possible to have equilibrium, causing its toppling.

Keywords: stability, bearing, stiffness, equilibrium, toppling.

\section{Resumo}

A estabilidade lateral de vigas pré-moldadas esbeltas durante as fases transitórias e em serviço deve ser avaliada, observando que a presença de imperfeições geométricas torna o problema da instabilidade mais susceptível. O objetivo principal deste trabalho é avaliar o comportamento de vigas de concreto sobre apoios elastoméricos, considerando a influência de variáveis como: a resistência do concreto, a ação do vento e a rigidez a compressão das almofadas de apoio. Para a análise numérica não-linear utiliza-se neste trabalho o programa computacional ANSYS, baseado no método dos elementos finitos. As análises mostram que a influência da resistência do concreto é significante na estabilidade lateral da viga. A ação do vento pode ser responsável pela redução da área de contato entre a viga e a almofada de apoio (efeito de lift-off). Finalmente, a combinação destes fatores pode resultar em uma situação crítica de tensões na viga, para a qual não há condição de equilíbrio, resultando no tombamento da viga.

Palavras-chave: estabilidade, apoio, rigidez, equilíbrio, tombamento. 


\section{Introduction}

In recent years, there have been reported cases in the literature of occurrences involving the collapse of precast beams during transitory phases. Precast concrete elements are submitted, during their working life, to situations and stresses that are characteristic of these phases, which may not have been foreseen in their design. In particular, in the case of beams destined to cover large spans, such as bridge beams, viaducts and large structures, the worrying problem of lateral stability arises. Due to the determinants of the lifting device and the transport vehicles, these cross sectional elements that are evermore optimized, present a considerable slenderness and great length. The mechanical length of the slender beams is different to non-slender beams. Beams that are very slender, along with those that are moderately slender are subject to the effects of lateral instability, which are inherent to cross section dimensions and design (Girija and Menon [1]).

In addition, the existence of initial geometric imperfections, due to failures in the concreting, in the application of prestressing and in the positioning of the lifting points, go onto aggravate the problem further. These imperfections generate additional eccentricities in the beam, which intensify the effects of the transitory phases.

The context of this study is found in the situation where the beam is supported on elastomeric bearing pads without any lateral bracing. In this case, there is no restriction to the rigid body rotation, and further still, the flexibility of the elastomeric support device together with some stresses (such as wind load) are capable of adding to the beam an extremely unstable configuration, which may lead to a possible collapse.

The accidents reported by Tremblay and Mitchell [2], Oesterle et al. [3] and Bairán and Cladera [4] relate to the phase in which the beam is positioned on supports. In Tremblay and Mitchell [2] and Oesterle et al. [3], the lateral bracing employed was insufficient to prevent the toppling of the beam. In Bairán and Cladera [4],

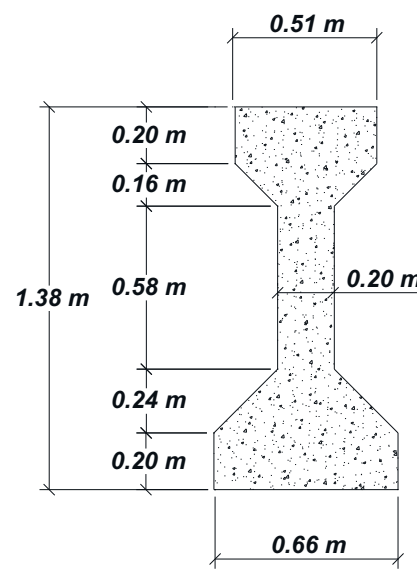

(a) Real section

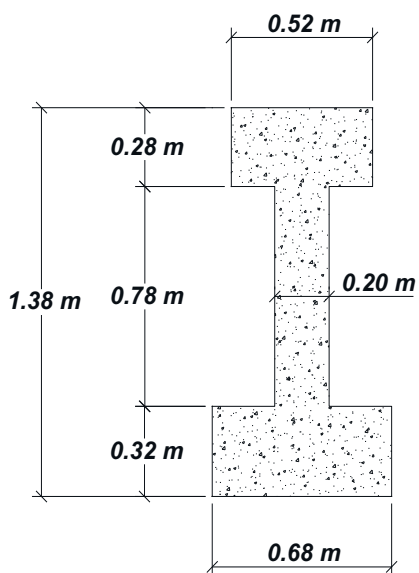

(b) Idealized section
Source: Authors (2017)

\section{Figure 1}

Cross section modified from the AASHTO beam Type IV the elastomeric support device does not offer sufficient stiffness in terms of the toppling of the beam due to the incorrect design of the pad, or that the pad was correctly designed, but positioned in an incorrect manner. The researchers Burgoyne and Stratford [5] along with Plaut and Moen [6], and Cardoso and Lima [7] deal with the lateral instability of beams from precast concrete on deformable supports. The authors show that the stiffness of the support significantly influences the equilibrium and stability of the beam, mainly when faced with wind loads.

Lee [8] studied the lateral instability of precast beams with initial sweep supported by elastomeric bearing pads with a regard to critical weight. In his article, the author has presented an equation to calculate the critical load that provides an unstable condition to the beam. As expected, the author concluded that the critical load decreased importantly as the initial sweep increased.

Lee et al. [9] analyzed precast beams during construction under wind loads. The authors investigated the influence of length and section properties on critical wind loads that provides rollover instability to the beam. The results have shown that the critical wind load was strongly influenced by the length of the girder, but with no influence by section properties.

In light of the above, this study aims at evaluating the lateral stability of the AASHTO beam Type IV positioned on FDOT pads Type $A$ and FDOT Type $B$, taking into consideration wind loads. Furthermore, the intention is to evaluate the influence of the characteristic strength and of physical linearity of the concrete along with the compression stiffness of the pad, keeping in mind the loss of contact between the beam and the support and the compression limit of the employed bearing pad.

\section{Material and methods}

This study performs a numerical analysis through the computer modeling program ANSYS in finite elements. A simulation was run where the standardized section beam AASHTO Type IV, presented in Figure 1, with $32 \mathrm{~m}$ in length, is supported on pads also standardized FDOT Type A and FDOT Type B, for which the dimensions are presented on Table 1.

The AASHTO Type IV beam was fabricated with an initial geometric imperfection, which represented the maximum limit permitted by $\mathrm{PCl}$ [10]: $10 \mathrm{~mm}$ for every $10 \mathrm{~m}$ of beam length, which results in a total of $32 \mathrm{~mm}$. The initial geometric imperfection is schematically represented in Figure 2.

In the case of steel-reinforced elastomeric bearing pads, the compression stiffness or roll stiffness is sometimes difficult to estimate

\section{Table 1}

Dimensions and characteristics of the analyzed bearing pads

\begin{tabular}{ccc}
\hline \multirow{2}{*}{ Dimension/characteristic } & \multicolumn{2}{c}{ Bearing pad } \\
\cline { 2 - 3 } & A & B \\
\hline Length, L $(\mathrm{cm})$ & 60 & 60 \\
Width, W $(\mathrm{cm})$ & 28 & 36 \\
Height, H $(\mathrm{cm})$ & 4.8 & 6.5 \\
Quantity of steel plates & 3 & 4 \\
\hline
\end{tabular}

Source: Authors (2017) 


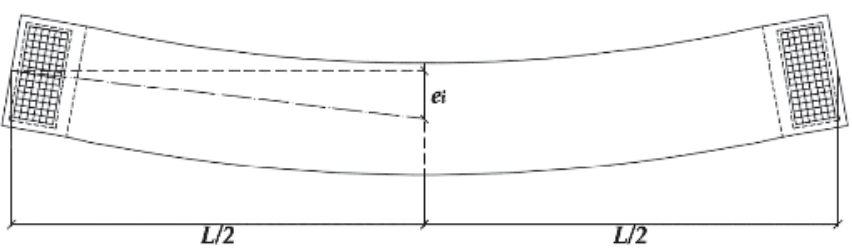

Source: Authors (2017)

\section{Figure 2}

Representation of the initial eccentricity on the beam (out of scale)

because of complex deformations of the elastomer. A method of numerical analysis for estimating the axial and roll stiffness of bearing pads is presented by Harper and Consolazio [11], which consider the pad modeled as a grillage of compression-only axial springs. The grillage method was partially derived from roll stiffness data measured in an experimental study, and accurately capture both the nonlinear moment-rotation behavior caused by lift off of the beam from the pad and the observed sensitivity of roll stiffness to initial compressive loading caused by self-weight of the beam. In order to numerically present the elastomeric bearing pads, the simplified model proposed by Harper and Consolazio [11] was adopted. The authors present a simplified model to calculate the axial stiffness and the rotation of the elastomeric rectangular bearing pads. According to the authors, when dealing with problems of lateral stability, torsional stiffness is not related directly and shear stiffness can be determined directly through basic principles that are already understood.

When the beam is placed in its service position on the padded supports, the pad is stretched and there is contact between the whole surface of the beam and the elastomer. In this situation, the roll stiffness of the pad presents a linear relationship. However, as the rate of the rotation angle on the beam increases, it loses part of its contact with the pad (lift off) and its roll stiffness is no longer linear, but rather non-linear (Figure 3) (Harper and Consolazio [11]).

The study of Harper and Consolazio [11] proposed a simplified numerical model for determining the roll stiffness of elastomeric pads. This model considers the pad as a rigid grid responsible for uniting compression springs of different stiffness, as presented in Figure 4. This grid model divides the pad into small rectangular
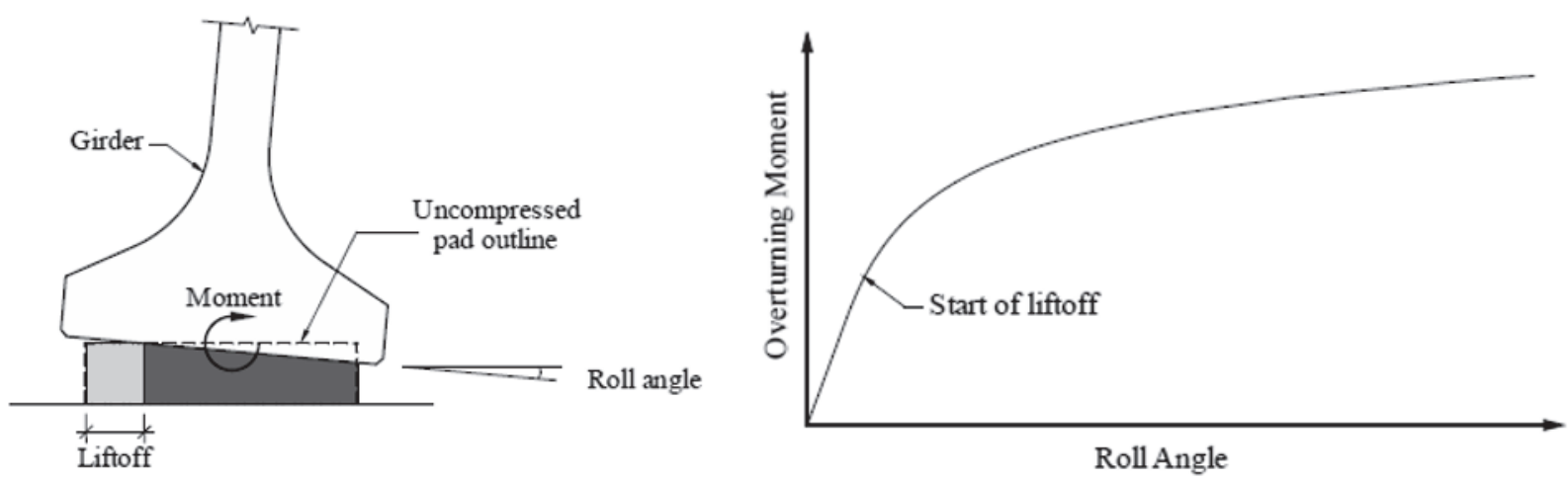

Source: Harper and Consolazio (2013)

\section{Figure 3}

Loss of contact of beam with the elastomer
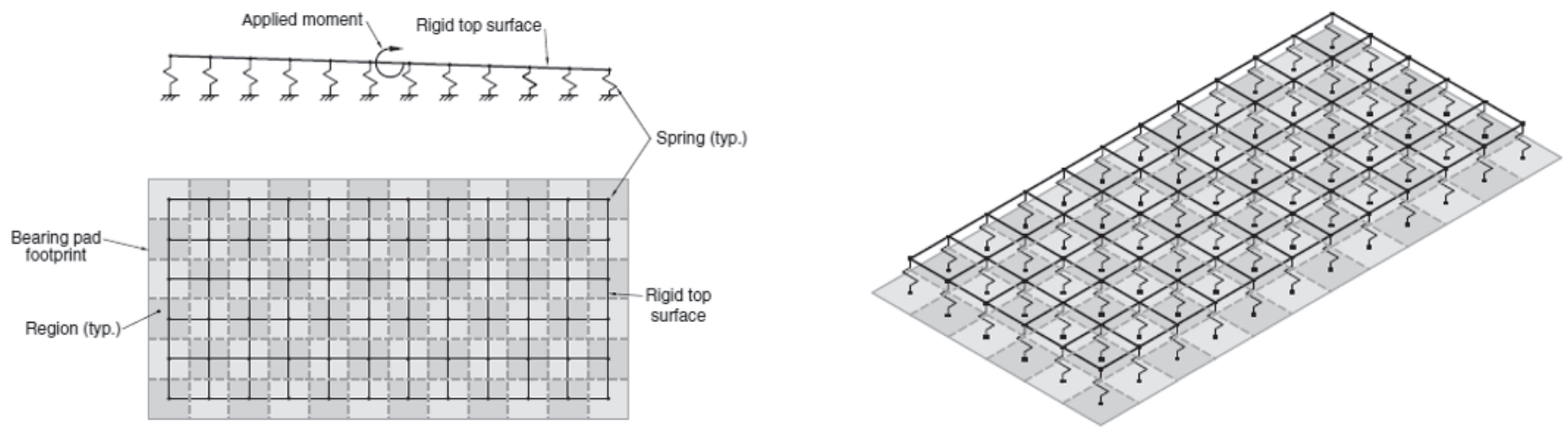

Source: Harper and Consolazio (2013)

Figure 4

Loss of contact of beam with the elastomer 


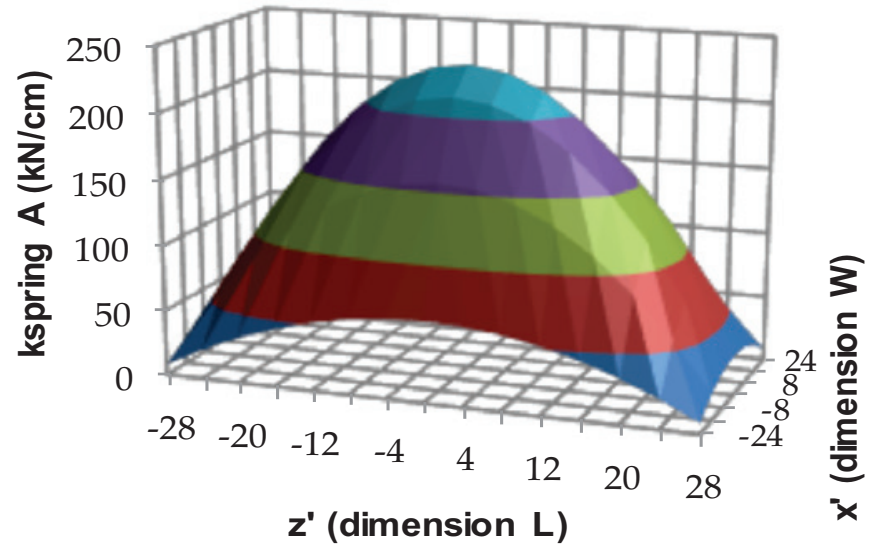

(a) Pad A

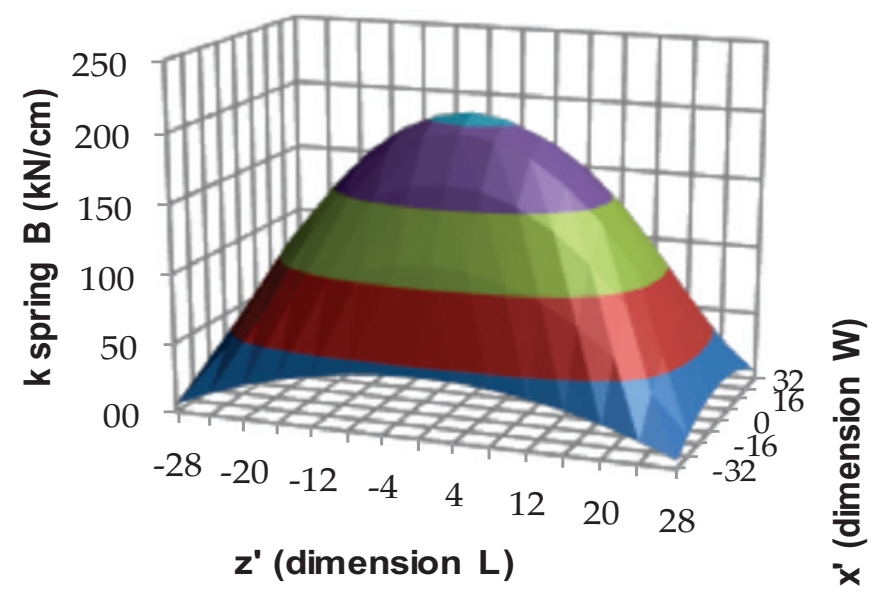

(a) Pad B

Source: Authors (2017)

\section{Figure 5}

Stiffness distribution

regions and each one is associated to a stiffness compression spring different to the others. Compression springs were used to represent the loss of contact of the beam with the pad.

According to the authors, at particular levels of compression, the behavior of the pad becomes non-linear, as the bulging caused by the compression reduces the thickness of the layer and stiffens the pad. In addition, the compression stiffness varies according to the distance in relation to the center of the pad. In this manner, the simplified model proposed by Harper and Consolazio [11] considers the different behaviors in relation to the distance from the center of the pad, as shown in Equation (1):

$k_{\text {spring }}\left(x^{\prime}, z^{\prime}\right)=A_{\text {region }} \cdot\left(\frac{k_{\text {bearing pad }}}{A_{\text {bearing pad }}}\right) \cdot\left[1-\left(x^{\prime}\right)^{2}\right] \cdot\left[1-\left(z^{\prime}\right)^{2}\right]$

Where: $k_{\text {spring }}\left(x^{\prime}, z^{\prime}\right)$ is the value of the spring stiffness concerning its position relative to the center of the pad; $A_{\text {region }}$ is the area of the region of influence of a spring; $k_{\text {bearing pad }}$ is the axial compression stiffness of the pad; $A_{\text {bearing pad }}$ is the area of the pad; $x^{\prime}$ and $z^{\prime}$ are the normalized coordinates of the pad.

The model proposed by Harper and Consolazio [11] was validated in this study by use of ANSYS. Starting out from the axial compression stiffness that is already known for pad A of $10991 \mathrm{kN} / 10^{-2}$ $\mathrm{m}$ and for pad $\mathrm{B}$ of $12512 \mathrm{kN} / 10^{-2} \mathrm{~m}$, the pads were designed as stiff grids responsible for uniting the springs. The results obtained from displacement and rotating angles of the pad were close to those presented by the authors. Pad A was designed as a grid with 105 compression springs $(7 \times 15)$, with a region area equal to 16 $\mathrm{cm}^{2}$. Pad B was designed as a grid with 135 compression springs $(9 \times 15)$, with a region area equal to $16 \mathrm{~cm}^{2}$.

For the springs, the element LINK180 was used, with the "compress only" option activated, that is, in this situation, the springs do not work if they are tensioned, and thus they do not contribute numerically to the behaviour of the pad. In terms of the stiff grid, the element BEAM188 was used. The nodes on the lower parts of the model were embedded. As the element LINK180 is a truss element, so that the model does not become unstable, displacements were impeded on the longitudinal (UX) and transversal (UZ) on the upper nodes of the grid. In the interest of maintaining the grid rigid, an elasticity module was adopted that carried the same value as that of steel $\left(2.0 \cdot 10^{8} \mathrm{kN} / \mathrm{m}^{2}\right)$. A rectangular transversal section was chosen, for which the dimensions were defined after various tests. The transversal section that provided rigidity to the grid was $25 \mathrm{~mm} \times 90 \mathrm{~mm}$. Through use of Equation (1), the calculation was made for the stiffness of each spring, taking into consideration its position that has been normalized in relation to the center of the pad. As affirmed by Harper and Consolazio [11], Equation (1) provides a satisfactory approximation of the format for the distribution of the axial stiffness on the pad; however, it does not provide values of the true magnitude of this stiffness. Therefore, it was necessary to include a correction factor (CF) to the stiffness of each spring, since the total value of the axial stiffness on the pad was less than the real value. This correction factor was obtained through adding the compression stiffness of each spring calculated using Equation (1) and then dividing this by the axial compression stiffness known through this sum. For pad $A$, the correction factor was equal to 2.2223 and pad $B, 2.2312$ (Cardoso [12]). Figure 5 presents the stiffness distribution on pads $A$ and $B$.

In dealing with the element LINK180, the stiffness was considered in the definition of the modulus of elasticity (E) of each spring, since the stiffness of the truss element is given through Equation (2).

$k_{\text {spring }}=\frac{E \cdot A}{L} \rightarrow E=\frac{k_{\text {spring }} \cdot L}{A}$

Where: $L$ is the length of the bar, which here is the height of the pad; $A$ is the area of the cross section of the bar, defined as a unit set. Table 2 presents the values of compression stiffness, corrected by the correction factor and the value of the elasticity module of the springs from the first quadrant of pad A. Similar procedures were made for the pad $B$ in order to obtain the compression stiffness of their springs. 
Once the simplified models for pads A and B were concluded, the beams were designed as an arc between two straight segments under which the pads were positioned. It was necessary to proceed in this manner, in order that the beam nodes coincide exactly with the nodes on the pad in accordance with the simplified model.

Lee et al. [9] presented an equation to estimate the critical wind load that provides an rollover instability to the beam (Equation (3)).

$(w L)\left[y_{c} \theta_{s}+\frac{w \theta_{s} L^{4}}{120 E I_{y}}+\frac{F_{w} L^{4}}{120 E I_{y}}\right]+\left(F_{w} L\right)\left[y_{c}-\frac{F_{w} L^{4}}{120 E I_{y}} \theta_{s}\right]=2 k_{r} \theta_{s}$

Where: $(w L)$ is the total self-weight of the beam; $y_{c}$ is the height of the centre of gravity of the beam; $\theta_{s}$ is the rotational angle at support; $w$ is the self-weight of girder per unit length; $L$ is the length of the beam; $E$ is the modulus of elasticity of the beam; $I_{y}$ is the smaller moment of inertia of the beam; $F_{w}$ is the wind load per unit length; $\mathrm{k}_{\mathrm{r}}$ is the rotational stiffness of bearing pad.
In order to model the beam, the three-dimensional element SOLID65 was employed. In the longitudinal direction, concerning the support regions, a more refined mesh was adopted, and in the region of the beam arc, a less discretized mesh was used.

From the standpoint of the beam on supports, one can state that the only load that acts on the structure is its self-weight, which was applied by the inertia command from ANSYS. In all the numerical analyses, emphasis was placed on geometric non-linearity. In cases of lateral instability, the emphasis placed upon large displacements is of great importance, in order that the problem is correctly represented.

Three characteristic strength for the concrete $\left(f_{c k}\right)$ were adopted, namely, 27.5, 45 and $90 \mathrm{MPa}$. The modulus of elasticity of the concrete initially adopted for the beam were respectively, 29370 , 37570 and $53130 \mathrm{MPa}$.

In an attempt to simulate the behavior of the cracked beam and the loss of its resistance capacity due to the physical non-linearity

\section{Table 2}

Corrected compression stiffness and elasticity module for the springs of the first quadrant of pad A

\begin{tabular}{|c|c|c|c|c|c|}
\hline Spring & Node & $\mathrm{x}^{\prime}$ & $z^{\prime}$ & $\begin{array}{c}\text { kspring } \\
\left(\mathrm{kN} / \cdot 10^{-2} \mathrm{~m}\right)\end{array}$ & $\begin{array}{c}E \\
\left(k N / \cdot 10^{-4} \mathrm{~m}^{2}\right) \\
\end{array}$ \\
\hline 1 & 1 & -0.857 & -0.933 & 7.954 & 38.181 \\
\hline 2 & 3 & -0.571 & -0.933 & 20.192 & 96.921 \\
\hline 3 & 5 & -0.286 & -0.933 & 27.534 & 132.165 \\
\hline 4 & 7 & 0.000 & -0.933 & 29.982 & 143.913 \\
\hline 8 & 15 & -0.857 & -0.800 & 22.217 & 106.643 \\
\hline 9 & 17 & -0.571 & -0.800 & 56.398 & 270.710 \\
\hline 10 & 19 & -0.286 & -0.800 & 76.906 & 369.150 \\
\hline 11 & 21 & 0.000 & -0.800 & 83.742 & 401.963 \\
\hline 15 & 29 & -0.857 & -0.667 & 34.286 & 164.573 \\
\hline 16 & 31 & -0.571 & -0.667 & 87.034 & 417.762 \\
\hline 17 & 33 & -0.286 & -0.667 & 118.682 & 569.676 \\
\hline 18 & 35 & 0.000 & -0.667 & 129.232 & 620.313 \\
\hline 22 & 43 & -0.857 & -0.533 & 44.160 & 211.970 \\
\hline 23 & 45 & -0.571 & -0.533 & 112.099 & 538.078 \\
\hline 24 & 47 & -0.286 & -0.533 & 152.863 & 733.742 \\
\hline 25 & 49 & 0.000 & -0.533 & 166.451 & 798.964 \\
\hline 29 & 57 & -0.857 & -0.400 & 51.840 & 248.834 \\
\hline 30 & 59 & -0.571 & -0.400 & 131.595 & 631.656 \\
\hline 31 & 61 & -0.286 & -0.400 & 179.448 & 861.349 \\
\hline 32 & 63 & 0.000 & -0.400 & 195.399 & 937.914 \\
\hline 36 & 71 & -0.857 & -0.267 & 57.326 & 275.166 \\
\hline 37 & 73 & -0.571 & -0.267 & 145.520 & 698.498 \\
\hline 38 & 75 & -0.286 & -0.267 & 198.437 & 952.498 \\
\hline 39 & 77 & 0.000 & -0.267 & 216.076 & 1037.164 \\
\hline 43 & 85 & -0.857 & -0.133 & 60.618 & 290.965 \\
\hline 44 & 87 & -0.571 & -0.133 & 153.876 & 738.603 \\
\hline 45 & 89 & -0.286 & -0.133 & 209.830 & 1007.186 \\
\hline 46 & 91 & 0.000 & -0.133 & 228.482 & 1096.714 \\
\hline 50 & 99 & -0.857 & 0.000 & 61.715 & 296.231 \\
\hline 51 & 101 & -0.571 & 0.000 & 156.661 & 751.972 \\
\hline 52 & 103 & -0.286 & 0.000 & 213.628 & 1025.416 \\
\hline 53 & 105 & 0.000 & 0.000 & 232.618 & 1116.564 \\
\hline
\end{tabular}

Source: Authors (2017) 
of the concrete, a physical non-linear analysis was performed on ANSYS. In order to perform this analysis, the model for concrete from the element SOLID65 was used. The stress - strain curve was obtained through the definition of six points, for which the coordinates were calculated from parametric equations that relate the characteristic strength of the concrete with its initial or tangent modulus of elasticity.

To use the model for concrete on ANSYS, it was necessary to define four parameters relevant to the behavior of stressed concrete. The two parameters refer to the shear stress transferred to the open and closed cracks. For these variables, the values of 0.2 and 1.0 were adopted, respectively. The two remaining parameters relate to the stress on the cracks and crushing of the concrete, for which the values of one tenth of the strength of the concrete and $(-1.0)$, were defined, respectively.

It is known that under pre-service conditions, even though not desirable, there can occur loads arising from wind in different magnitudes and directions. Therefore, the occurrence of wind loads on the AASHTO beam Type IV was analyzed, on the elastomeric pads $A$ and $B$.

In the interest of representing the stress generated by wind loads, consideration was given to a horizontal stress load acting upon the direction of the initial eccentricity of the beam. The researchers Plaut and Moen [6] adopted a pressure of 2.4 $\mathrm{kPa}$, which corresponds to the basic wind velocity of $45 \mathrm{~m} / \mathrm{s}$. In this study, a pressure of $2.0 \mathrm{kPa}$ was adopted, corresponding to a basic velocity of $37.5 \mathrm{~m} / \mathrm{s}$, and the resulting stress was applied in a simplistic form to the upper surface of the beam in the middle of the span. The total wind stress $(88 \mathrm{kN})$ was applied in four load steps, in order to obtain the structural behavior that is subject to different wind pressures, 0.5, 1.0, 1.5 and $2.0 \mathrm{kPa}$.

\section{Results and discussions}

Figure 6 presents the behavior of pads $A$ and $B$, respectively, through consideration of an AASHTO beam Type IV, with eccentricity of $3.2 \mathrm{~cm}$, considering only the non-linear geometric analysis. The shaded area represents the region where there is no support reaction on the pad, in other words, the region where there is no contact between the beam and the pad.

The stiffness of the beam plays an important role in terms of its stability. The wind represents a significant additional stress to the stability of the beam on pad A. In this sense, it is noteworthy to mention the stiffness limit of the elastomeric pad (Equation (4)), which has a value of $11 \mathrm{MPa}$. Hence, it is interesting to check it for the most unfavorable situation: beam with $\mathrm{f}_{\mathrm{ck}}=27.5 \mathrm{MPa}$ subjected to wind pressure equal to $2.0 \mathrm{kPa}$.

$\sigma_{c, \lim }=\frac{N}{A} \rightarrow A=\frac{N}{\sigma_{c, l i m}}$

Where: $\sigma_{\text {clim }}$ is the compression stress limit on the pad, equal to $11 \mathrm{MPa} ; \mathrm{N}$ is the normal stress that acts on the pad. In this case, we have the total weight of the beam placed on two pads, in other words, the normal stress is half of the total weight of the beam that adds up to approximately, $208 \mathrm{kN}$; $\mathrm{A}$ is the area being demanded from the pad.

The value of $A$ is approximately $1,89 \cdot 10^{-2} \mathrm{~m}^{2}$. The bearing pad $A$ is $1,68 \cdot 10^{-1} \mathrm{~m}^{2}$ and its area was discretized on the simplified model, with 105 area regions measuring $1,6 \cdot 10^{-3} \mathrm{~m}^{2}$. Therefore, area A that is being demanded from the pad corresponds to 12 regions on the simplified model. Hence, as can be noted in Figure 6, in the last case for wind pressure equal to $2.0 \mathrm{kPa}$ and $\mathrm{f}_{\mathrm{ck}}$ equal to $27.5 \mathrm{MPa}$, still under the most unfavorable condition for the beam on bearing pad $\mathrm{A}$, one was able to establish the equilibrium and

Bearing pad A

(a) $f_{c k}=27.5 \mathrm{MPa}$

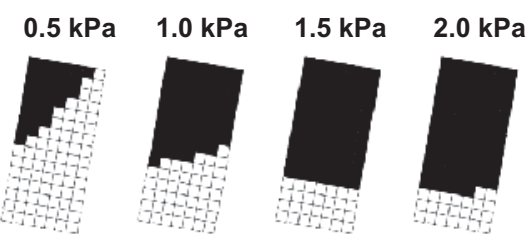

(a) $f_{c k}=27.5 \mathrm{MPa}$
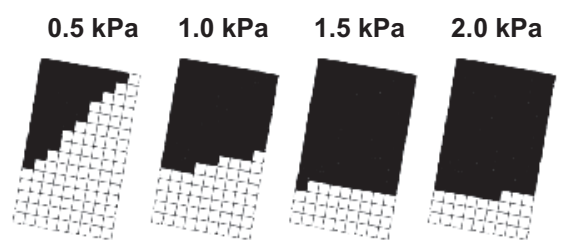

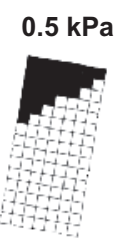

(b) $f_{c k}=45 \mathrm{MPa}$
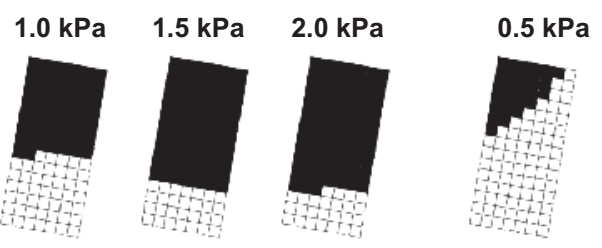

(c) $\mathrm{f}_{\mathrm{ck}}=90 \mathrm{MPa}$

Bearing pad B

(b) $\mathrm{f}_{\mathrm{ck}}=\mathbf{4 5 \mathrm { MPa }}$

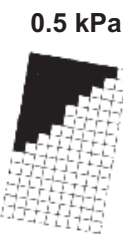

$1.0 \mathrm{kPa} \quad 1.5 \mathrm{kPa}$

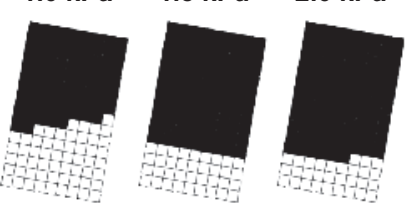

(c) $\mathrm{f}_{\mathrm{ck}}=90 \mathrm{MPa}$

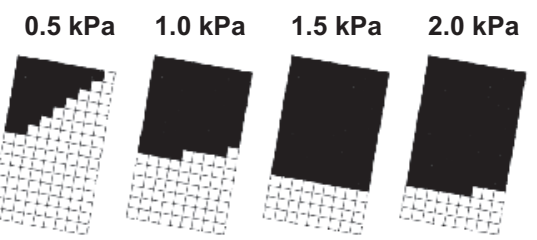

Source: Authors (2017)

Figure 6

Loss of contact on the AASHTO beam Type IV on pad A and B 
Table 3

Maximum vertical displacement on the AASHTO beam Type IV

\begin{tabular}{|c|c|c|c|c|c|c|c|c|c|c|c|c|}
\hline \multirow{3}{*}{$\begin{array}{l}\text { Wind } \\
\text { load } \\
(\mathrm{kPa})\end{array}$} & \multicolumn{12}{|c|}{ Maximum vertical displacement on the AASHTO beam Type IV $\left(\cdot 10^{-2} \mathrm{~m}\right)$} \\
\hline & \multicolumn{6}{|c|}{ Bearing Pad A } & \multicolumn{6}{|c|}{ Bearing Pad B } \\
\hline & $\begin{array}{l}27.5 \\
\mathrm{MPa}\end{array}$ & $\begin{array}{c}27.5 \\
\text { MPa } \\
\text { with PNL }\end{array}$ & $\begin{array}{c}45 \\
\mathrm{MPa}\end{array}$ & $\begin{array}{c}45 \\
\mathrm{MPa} \\
\text { with PNL }\end{array}$ & $\begin{array}{c}90 \\
\mathrm{MPa}\end{array}$ & $\begin{array}{c}90 \\
\mathrm{MPa} \\
\text { with PNL }\end{array}$ & $\begin{array}{l}27.5 \\
\mathrm{MPa}\end{array}$ & $\begin{array}{c}27.5 \\
\text { MPa } \\
\text { with PNL }\end{array}$ & $\begin{array}{c}45 \\
\mathrm{MPa}\end{array}$ & $\begin{array}{c}45 \\
\mathrm{MPa} \\
\text { with PNL }\end{array}$ & $\begin{array}{c}90 \\
\mathrm{MPa}\end{array}$ & $\begin{array}{c}90 \\
\text { MPa } \\
\text { with PNL }\end{array}$ \\
\hline 0.0 & 2.6288 & - & 2.0512 & - & 1.4514 & 1.4737 & 2.5694 & - & 2.0053 & - & 1.4189 & 1.4428 \\
\hline 0.5 & 2.7307 & - & 2.1333 & - & 1.5159 & 1.5417 & 2.6731 & - & 2.0899 & - & 1.4841 & 1.5118 \\
\hline 1.0 & 2.9161 & - & 2.2907 & - & 1.6459 & 1.6792 & 2.8536 & - & 2.2396 & - & 1.6073 & 1.6425 \\
\hline 1.5 & 3.3357 & - & 2.6463 & - & 1.9591 & - & 3.2299 & - & 2.5699 & - & 1.8867 & - \\
\hline 2.0 & 3.6436 & - & 2.9236 & - & 2.1936 & - & 3.5258 & - & 2.8309 & - & 2.1549 & - \\
\hline
\end{tabular}

Source: Authors (2017)

Table 4

Maximum horizontal displacement on the AASHTO beam Type IV

\begin{tabular}{|c|c|c|c|c|c|c|c|c|c|c|c|c|}
\hline \multirow{3}{*}{$\begin{array}{l}\text { Wind } \\
\text { load } \\
\text { (kPa) }\end{array}$} & \multicolumn{12}{|c|}{ Maximum horizontal displacement on the AASHTO beam Type IV $\left(\cdot 10^{-2} \mathrm{~m}\right)$} \\
\hline & \multicolumn{6}{|c|}{ Bearing Pad A } & \multicolumn{6}{|c|}{ Bearing Pad B } \\
\hline & $\begin{array}{l}27.5 \\
\mathrm{MPa}\end{array}$ & $\begin{array}{c}27.5 \\
\text { MPa } \\
\text { with PNL }\end{array}$ & $\begin{array}{c}45 \\
\mathrm{MPa}\end{array}$ & $\begin{array}{c}45 \\
\mathrm{MPa} \\
\text { with PNL }\end{array}$ & $\begin{array}{c}90 \\
\mathrm{MPa}\end{array}$ & $\begin{array}{c}90 \\
\mathrm{MPa} \\
\text { with PNL }\end{array}$ & $\begin{array}{l}27.5 \\
\mathrm{MPa}\end{array}$ & $\begin{array}{c}27.5 \\
\text { MPa } \\
\text { with PNL }\end{array}$ & $\begin{array}{c}45 \\
\mathrm{MPa}\end{array}$ & $\begin{array}{c}45 \\
\mathrm{MPa} \\
\text { with PNL }\end{array}$ & $\begin{array}{c}90 \\
\mathrm{MPa}\end{array}$ & $\begin{array}{c}90 \\
\mathrm{MPa} \\
\text { with PNL }\end{array}$ \\
\hline 0.0 & 0.2789 & - & 0.2206 & - & 0.1624 & 0.1846 & 0.2653 & - & 0.2087 & - & 0.1521 & 0.1742 \\
\hline 0.5 & 1.5716 & - & 1.2321 & - & 0.8964 & 1.0284 & 1.5314 & - & 1.2052 & - & 0.8721 & 1.0064 \\
\hline 1.0 & 3.2790 & - & 2.6313 & - & 1.9795 & 2.2382 & 3.1590 & - & 2.5249 & - & 1.8936 & 2.1547 \\
\hline 1.5 & 6.5847 & - & 5.4408 & - & 4.4064 & - & 6.1245 & - & 5.1200 & - & 4.0513 & - \\
\hline 2.0 & 9.0760 & - & 7.7171 & - & 6.3519 & - & 8.5190 & - & 8.2641 & - & 6.2044 & - \\
\hline
\end{tabular}

stability of the beam and meet the compression limit of the elastomeric pad. As the pad region under demand corresponds to 23 regions, i.e., $3,68 \cdot 10^{-2} \mathrm{~m}^{2}$.

By performing the same analysis for the compression limit on the elastomeric pad for bearing pad B under the situation of highest demand, one notes that here also this limit is met. Its most critical situation occurs when the wind pressure that acts upon it corresponds to $2.0 \mathrm{kPa}$. In this case, an area of $4,80 \cdot 10^{-2} \mathrm{~m}^{2}$ (23 regions) still effectively functions to guarantee the stability of the beam and avoid toppling; this area is greater than the $1,89 \cdot 10^{-2} \mathrm{~m}^{2}$ necessary in order that the limit is met.

Table 3 and Table 4 and Figure 7 and Figure 8 present the maximum vertical and horizontal displacements obtained on the AASHTO beam Type IV for the four wind pressures analyzed along with the physical and geometrical non-linear analyses. Due to the level of cracking reached in the physical non-linear analyses (PNL) with $\mathrm{f}_{\mathrm{ck}}$ equal to $27.5 \mathrm{MPa}$ and $45 \mathrm{MPa}$, there was no numerical convergence and no results were obtained for these strength

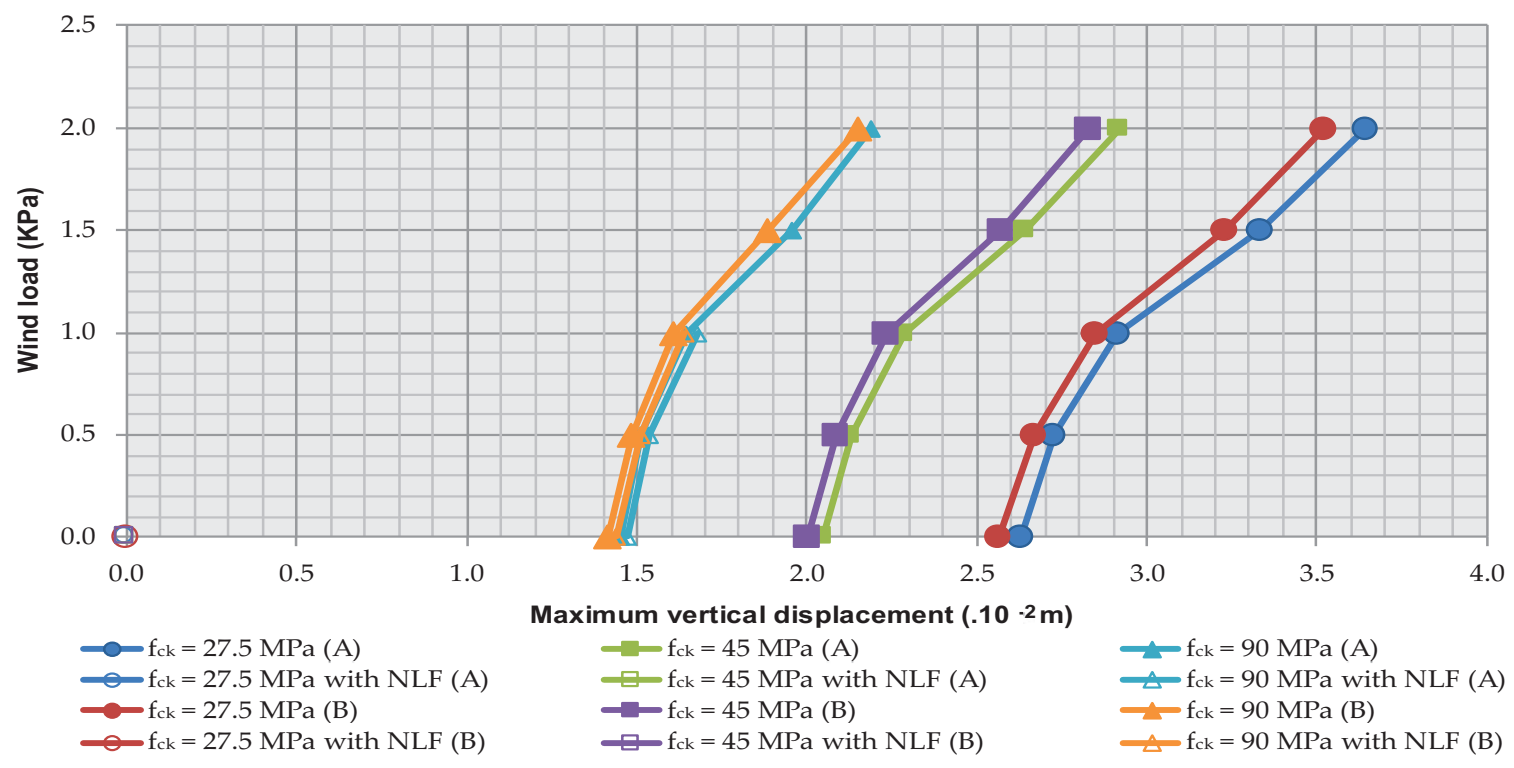

Source: Authors (2017)

Figure 7

Maximum vertical displacement on the AASHTO beam Type IV 


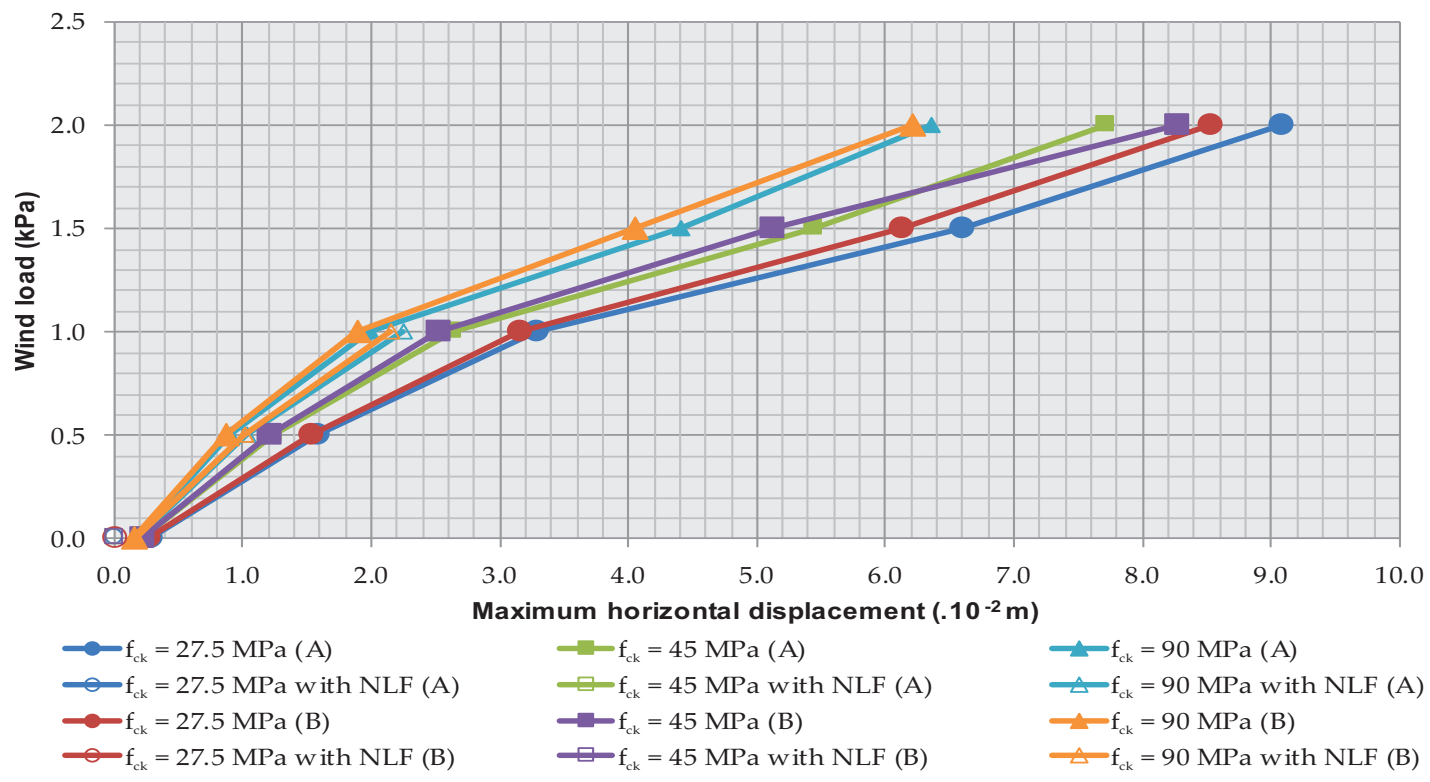

Source: Authors (2017)

\section{Figure 8}

Maximum horizontal displacement on the AASHTO beam Type IV

values of concrete. By considering the physical non-linearity for $f_{c k}$ equal to $90 \mathrm{MPa}$, it was possible to obtain the displacements for wind pressure at a maximum of $1.0 \mathrm{kPa}$. For pressures of 1.5 and $2.0 \mathrm{kPa}$, the computer program ANSYS did not find equilibrium on the beam under analysis. The wind pressure equal to $0.0 \mathrm{kPa}$ corresponds to the exclusive performance of the self-weight.

For the beam AASHTO Type IV with $\mathrm{f}_{\mathrm{ck}}$ equal to $90 \mathrm{MPa}$ and wind pressure of $1.0 \mathrm{kPa}$, the horizontal displacement obtained considering the geometric and physical nonlinearities was around $12 \%$ higher than that obtained only with nonlinear geometric analysis. The influence from the wind was more significant on the horizontal displacement, in the direction of the smaller inertia of the beam, mainly when compared to the value of the displacement with and without wind load.

When dealing with the lifting of precast elements there exists a safety factor, that is already consolidated in the literature, equal to 4.0, i.e., needs to consider in the suspending device design, a stress equal to four times the weight of the structure. Making an analogy of this same value of the safety factor with the situation of the beam on elastomeric supports, in relation to the compression limits of the elastomeric pads, one arrives at that presented in Equation (5).

$\sigma_{c, \text { lim }}=\frac{N}{A} \rightarrow A=\frac{4 \cdot\left(\frac{P}{2}\right)}{\sigma_{c, \text { lim }}}$

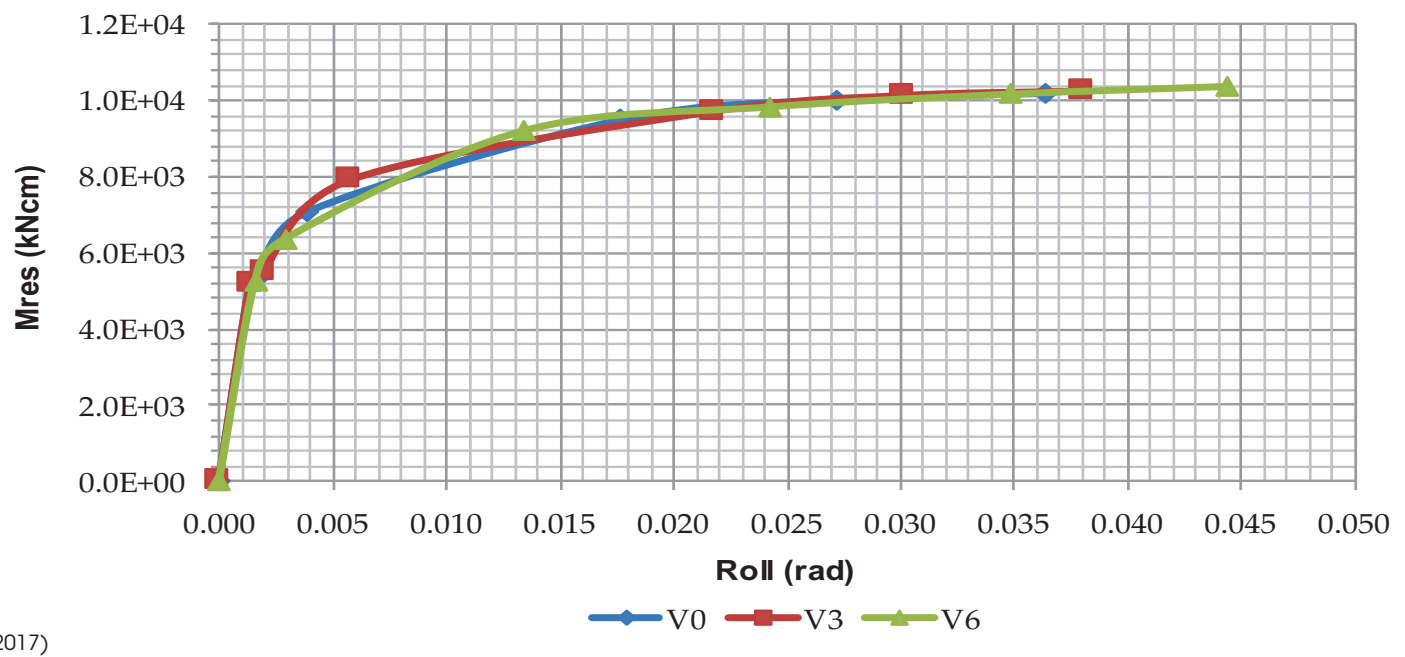

Source: Authors (2017)

Figure 9

Roll stiffness of bearing pad 


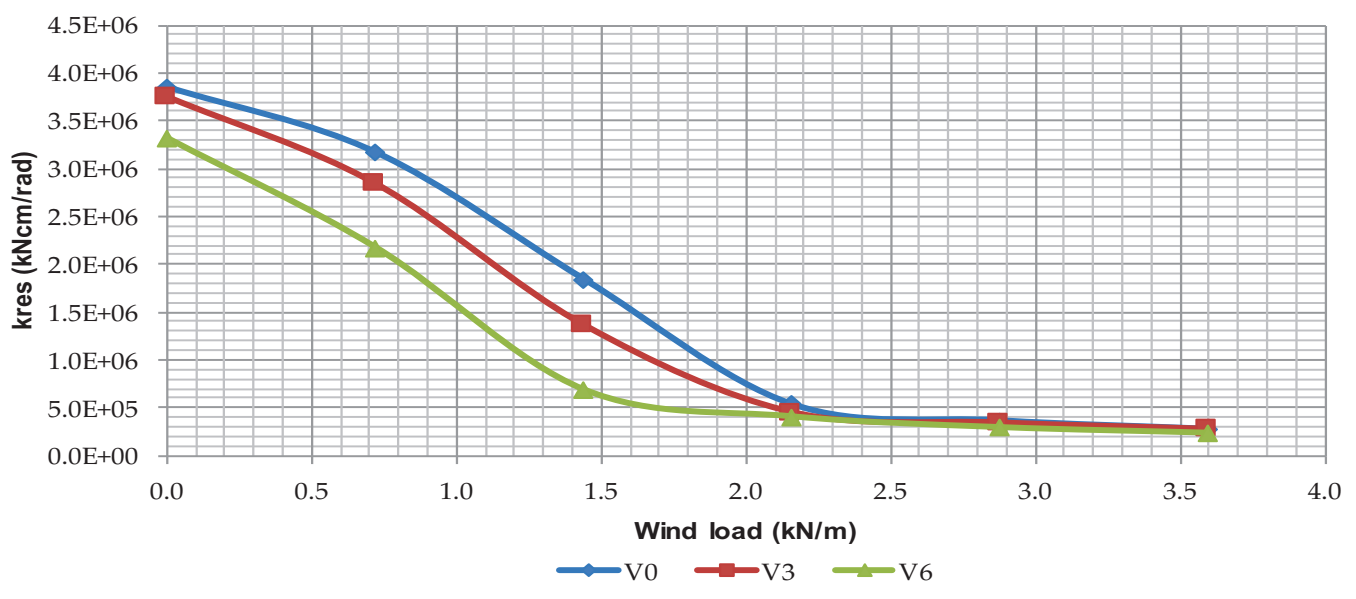

Source: Authors (2017)

\section{Figure 10 \\ Roll stiffness and wind load}

Therefore, so that this limit be met it would be necessary an area of $7,57 \cdot 10^{-2} \mathrm{~m}^{2}$ on the bearing pad, which corresponds to the 48 regions on the adopted simplified model. In this manner, for bearing pad $\mathrm{A}$, from the configurations for the support reactions presented in Figure 6, only those that correspond to a wind load of $0.5 \mathrm{kPa}$ met the compression limit of the elastomeric pad. For bearing pad $\mathrm{B}$, wind stresses of up to $1.0 \mathrm{kPa}$ can be used to meet the compression limit of the elastomeric pad.

The authors Burgoyne and Stratford (2001) mention in their study a safety factor equal to $10.0\left(P_{\text {crit }} / P\right)$, in order to avoid the rotation of the beam on its supports. At first, one can consider the value to be too high for the safety factor. The authors, therefore justify that the geometric imperfections, which are not considered during the design, can introduce additional stresses to the beam, which can be avoided by the choice of an adequate support pad.

Comparing the previous beam (named V3) with similar beams, but with different geometric imperfections, it is possible to know the rotation behavior of the bearing pad, which roll stiffness is shown in Figure 9. The beam V0 is the same beam AASHTO Type IV, but with no initial eccentricity. The beam named V6 is the beam which initial imperfection approximates that recommended by Eurocode 2 [13], that is, L/300. Figure 10 shows the roll stiffness values for different wind loads. Significant reduction of roll stiffness of the bearing pad is noticed as the action of the initial imperfection and the increase of the wind pressure are considered together.

Lee et al. [9] concluded that a wind load of $3.6 \mathrm{kN} / \mathrm{m}$ would cause toppling of the beam. From Figure 10, considering the maximum roll stiffness $2.75 \mathrm{E}+05 \mathrm{kNcm} / \mathrm{rad}$ obtained for the beam V0 and substituting in Equation (3), one obtain a rotation of 0.019 rad that balances the acting moment with the resistant moment. According to Lee et al. [9], the rotation at the support of $0.0032 \mathrm{rad}$, equivalent to $0.001 \mathrm{rad}$ every $10 \mathrm{~m}$ in length, would be sufficient to retain the beam and prevent its toppling. From the analyses carried out in this work, considering physical non-linearity (PNL) and the $\mathrm{V} 3$ beam with initial imperfection of $3.2 \mathrm{~cm}$, the wind load that would cause its toppling would be 1.0 $\mathrm{kPa}$, that is, $1.375 \mathrm{kN} / \mathrm{m}$.

\section{Conclusions}

The study of the lateral stability of precast concrete beams is shown to be of extreme importance, especially in the transitory phases due to unforeseen demands on the design. Furthermore, the lateral stability has been pointed out as a cause of accidents already reported in the literature. In the case of the beam on flexible supports, such as elastomers, it is known that the pad is under greater demand in the region close to its center, as shown in the compression stiffness distribution.

The simplified model represented an extremely viable alternative for the elaboration of a pad model with solid elements associated with contact elements. The model with compression springs allowed the simulation of loss of contact between the beam and the elastomer, which produced a change in the position of the support reactions on the bearing pad.

The consideration made as to the wind load was shown to be a condition much more unfavorable in terms of contact loss between the beam and the pad. This was verified to be more stringent through the physical non-linear analysis, for which results were not possible for $f_{c k}$ equal to $27.5 \mathrm{MPa}$ and $\mathrm{f}_{\mathrm{ck}}$ equal to $45 \mathrm{MPa}$.

For the beam AASHTO Type IV with $\mathrm{f}_{\mathrm{ck}}=90 \mathrm{MPa}$ on bearing pad A, the total wind load produced loss of contact in $76 \%$ of the area of the bearing pad, whereas there was no loss of contact recorded when only the self-weight was acting on the beam . Regarding the horizontal displacements, for beam $\mathrm{V} 3$ with $\mathrm{f}_{\mathrm{ck}}=90 \mathrm{MPa}$ on bearing pads $A$ and $B$, the consideration of physical nonlinearity represented an increase of around $12 \%$ in these displacements in the middle of the span.

It is of the utmost importance to verify that the compressed area of the pad, reduced in the region of the beam with displacement (lift off), is capable of meeting its maximum compression limit.

\section{Acknowledgements}

The authors would like to thank CAPES for granting the scholarship on the Master Academic level and to FAPEMIG (Public Call 01/2015) for the financial support. 


\section{References}

[1] Girija, K.; Menon, D. Reduction in flexural strength in rectangular RC beams due to slenderness. Engineering Structures, 33 (8), 2011, p.2398-2406.

[2] Tremblay, R.; Mitchell, D. Collapse during Construction of a Precast Girder Bridge. Journal of Performance of Constructed Facilities, 20 (2), 2006, p.113-125.

[3] Oesterle, R. G., Sheehan, M. J., Lotfi, H. R., Corley, W. G. \& ROLLER, J. J. Investigation of red mountain freeway bridge girder colapse. Arizona Department of Transportation, Bridge Group, Skokie, Illinois. CTL Group Project No. 262291. 2007.

[4] Bairán, J. M.; Cladera, A. Collapse of a precast concrete beam for a light roof. Importance of elastomeric bearing pads in the element's stability. Engineering Failure Analysis, 39, 2014, p.188-199.

[5] Burgoyne, C. J.; Stratford, T. J. Lateral Instability of longspan prestressed concrete beams on flexible bearings. The Structural Engineer, 79 (6), 2001, p.23-26.

[6] Plaut, R. H; Moen, C. D. Stability of unbraced concrete beams on bearing pads including wind loading. Journal of Structural Engineering, 69, 2014, p.246-254.

[7] Cardoso, M. T. S. A.; Lima, M. C. V. Physical and geometrical non-linear behavior of precast beams on elastomeric supports. Revista IBRACON de Estruturas e Materiais, v. 1, n. 7,2018 , p. $183-202$.

[8] Lee, J. H. Evaluation of the lateral stability of precast beams on an elastic bearing support with a consideration of the initial sweep. Engineering Structures, 143, 2017, p.101-112.

[9] Lee, J. H., Kalkan, I., Lee, J. J. \& Cheung, J. H. (2017) Rollover instability of precast girders subjected to wind load. Magazine of Concrete Research, 69 (2), 68-83.

[10] Precast Concrete Institute. Committee on Tolerances. $\mathrm{PCl}$ Tolerance Manual for Precast and Prestressed Concrete Construction. 1st ed. Chicago, IL. 2000.

[11] Harper, Z. S.; Consolazio, G. R. (2013) Calculation method for quantifying axial and roll stiffnesses of rectangular steel-reinforced elastomeric bridge bearing pads. Journal of the Transportation Research Board, 2331, 3-13.

[12] Cardoso, M. T. S. A. Instabilidade lateral de vigas prémoldadas sobre apoios elastoméricos considerando o efeito das imperfeições geométricas. Dissertação (Mestrado). Faculdade de Engenharia Civil, Universidade Federal de Uberlândia, 2017.

[13] Comité Européen de Normalisation. NF EN 1992 (Français): Eurocode 2: Calcul des structures en béton. CEN, Bruxelles, 2004. 